\title{
A INTERPRETAÇÃO DAS LEIS E A RAZÃO DE ESTTADO
}




\section{A INTERPRETAÇÃO DAS LEIS E A RAZÃO DE ESTADO ${ }^{*}$}

Norberto Bobbio

1. - Como se sabe, a primeira resposta à constituição da política como atividade autônoma foi de caráter moral. O princípio da razão de Estado deu origem principalmente a um problema moral e já os primeiros teóricos o atacaram armados com as categorias do bom e do mau, do honesto e do desonesto. Desde então, a discussão inicial de toda teoria política se volta para as relações, ainda que estas já tenham sido resolvidas, entre valoração política e valoração moral. Do mesmo modo, um século depois, quando o pensamento filosófico começa a distinguir a atividade jurídica da atividade moral, em princípio confusas ou numa consideração moralista da justiça ou numa consideração legalista da atividade moral, o problema da distinção entre moral e direito será alçado à ordem do dia de qualquer exposição de filosofia jurídica. As relações entre política e direito têm sido muito menos observadas e, ainda que elas sejam visíveis a todos e que todos busquem aprofundá-las, até mesmo identificando, por vezes, as duas atividades ou reduzindo toda atividade jurídica a expressão ou instrumento da atividade política, ainda não se voltou no tempo para buscar descobrir os eventuais nexos, não digo entre regime político e ordenamento legislativo, que é algo óbvio e peculiar de cada história política e jurídica, mas entre teoria política e ciência jurídica, nexos que podem precisamente iluminar historicamente o campo obscuro das relações entre as atividades política e jurídica.

É fato que as teorias da razão de Estado não foram suficientemente estudadas de um ponto de vista jurídico: ainda assim, são muitos e interessantes os problemas jurídicos que elas levantam, a começar por aquele implícito na definição de razão de Estado como "superação do direito comum para fins de utilidade pública", que deveria ser enquadrado e, assim, aprofundado em relação ao antiquíssimo e hoje mais vivo do que nunca problema das relações entre direito público e direito privado. É certo que tais teorias representam um primeiro impulso para a formação da ciência do direito público como ramo autônomo da jurisprudência geral e é, de fato, tal ciência que está se constituindo na Alemanha no início do séc. XVII. Precisamente na Alemanha, como destacou Meinecke, ${ }^{2}$ a teoria da razão de Estado, um produto genuinamente

\footnotetext{
1 * Publicado originalmente em: Scritti giuridici in onore di Santi Romano. Vol. I - Filosofia e teoria generale del diritto. Diritto costituzionale. Pádua: CEDAM, 1939. Tradução de Antonio Roberto Sanches Jr. e Celso Naoto Kashiura Jr. Revisão de José Antonio Siqueira Pontes e Marcelo de Azevedo Granato.

2 MEINECKE, Die Idee der Staatsräson, München, 1925, p. 165.
} 
italiano, acolhida desde o início com desconfiança como algo estranho e não conforme à mentalidade alemã, acaba pouco a pouco assimilada com uma redução de seu conteúdo nas formas do saber jurídico. Enquanto a razão de Estado representa, para os teóricos italianos, um “excesso da jurisprudência", com o elemento político se sobrepondo ao elemento jurídico e, portanto, sendo por si mesma irredutível aos esquemas do direito, para Clapmarius, um teórico alemão, ela é definida, com uma expressão destinada a tornar-se célebre, como "jus dominationis"; ou seja, é identificada com o direito do soberano de eliminar o "jus commune seu ordinarium" por interesse público e, por meio dessa identificação, torna-se aceitável e manejável para os juristas.

2. - Das variadas influências das teorias da razão de Estado sobre a ciência do direito, vamos nos limitar a recordar um pequeno aspecto, precisamente a teoria da interpretatio politica, desenvolvida e seguida por alguns juristas. Trata-se de um episódio pouco conhecido da história da jurisprudência, que, ainda que não seja de grande alcance, merece um exame e algumas considerações.

A ciência do direito se resolve, para os juristas medievais, na interpretatio, qualquer que tenha sido o modo como essa "interpretatio" foi então entendida pelas escolas e pelos destinatários diversos e, às vezes, polemicamente contrastantes, ela foi sempre entendida num sentido bem mais amplo daquele atualmente em uso, compreendendo não apenas a mera exegese do texto ou processo de esclarecimento, mas ainda a extensão da lei a casos expressamente não previstos ou processo de adaptação e, por fim, também a elaboração do sistema jurídico, aquilo que hoje chamamos própria e exclusivamente de "ciência do direito". Mesmo nesse sentido mais amplo, a interpretatio representa e resume aquela atitude típica e tradicional do jurista frente à lei, isto é, a atitude de subordinação, que não consente ao jurista colocar-se acima da lei para julgá-la, mas o compele a aceitar sua autoridade e a obedecer ao seu comando, quase como se a lei fosse um dogma e ao jurista não coubesse outra função senão respeitá-lo e fazê-lo respeitar. A interpretatio comenta, amplifica, constrói, mas não valora; sua finalidade é o conhecimento da lei; a valoração da lei é, para ela, absolutamente estranha. No limite, se uma valoração pode ser encontrada já entre os escritores medievais, tal valoração é obra daqueles que se colocam fora do direito positivo, os filósofos, que, no entanto, resolvem toda valoração em valoração moral, não conhecendo outro critério valorativo senão aquele implícito na pergunta se a lei é justa ou injusta: da qual seguem outros e bem notórios problemas, quais seriam as leis justas, qual deveria ser o comportamento dos súditos em caso de lei injusta e daí por diante. Portanto uma valoração política das leis que integre a obra dos juristas não pode ser encontrada quer na ciência, que comenta e não valora, quer na filosofia, que não conhece outra valoração que não a valoração ética precisamente. É natural que a valoração política das leis, como função 
específica e própria do jurisconsulto, não poderia surgir enquanto o pensamento humano não reconhecesse à atividade política um valor autônomo, sendo, assim, capaz de formar um critério próprio de valoração. Isso aconteceu no mesmo período ao qual comumente se atribui a tomada de consciência da distinção entre política e moral.

3. - Valorar politicamente uma lei significa emitir um juízo sobre a sua oportunidade: isto é, sopesar a sua maior ou menor conveniência aos fins políticos que o Estado propõe perseguir, colocando-se num ponto de vista que não é mais subordinado, mas superordenado à lei, o mesmo ponto de vista do legislador quando da necessidade de criar novas leis ou modificar as existentes.

A majestade das leis romanas, reforçada pela proibição de comentá-las pelo próprio imperador Justiniano, tinha colocado o jurista medieval numa situação de inferioridade perante as leis e, apesar da amplitude das visões com que algumas vezes as adaptou aos tempos, ele jamais ousou colocar-se acima daquela autoridade para emitir juízos que pudessem de qualquer modo diminuí-la ou simplesmente fazer suspeitar de sua infalibilidade. Uma atitude crítica das leis não poderia surgir senão com a afirmação da crítica histórica. Era a crítica histórica que poderia tornar perceptível o problema da conveniência política de uma lei, suscitando a exigência de considerar a lei não mais como dogma apenas, mas também como fato histórico. Esse problema surgiu e se desenvolveu na era moderna e a atitude crítica perante as leis passadas e presentes dará origem àquela nova forma de saber que é a ciência da legislação, que tem papel importante na renovação jurídica iluminista. Mas bem antes da ciência da legislação, uma crítica das leis envolvendo um juízo sobre seu valor político foi sugerida por alguns juristas alemães, no início da idade moderna, nos novos e empolgantes debates sobre a razão de Estado, que colocam no primeiro plano da discussão teórica o problema político, induzindo assim a considerar nas leis o seu valor político, ou seja, a sua oportunidade; em seguida, essa crítica foi encorajada pela situação particular em que, depois da guerra dos trinta anos, encontrava-se a ciência jurídica alemã, perplexa acerca da oportunidade da recepção do direito romano e buscando encontrar as razões e fundar os motivos de um retorno ao antigo direito germânico. Para tanto, é reconhecida, ainda que num círculo restritíssimo de juristas, uma nova forma de interpretação das leis que, dada a identificação entre ciência e interpretação, pode certamente ser considerada como um aspecto particular da ciência jurídica: essa nova forma de interpretação é uniformemente chamada de interpretatio politica.

4. - A interpretação política não aparece nas numerosas obras sobre interpretação dos juristas do direito comum: a sistematização dada por eles a esse problema foi movida por um interesse exclusivamente lógico e prático, de modo que os vários tipos de interpretação corres- 
pondiam ou à argumentação lógica neles usada ou aos diferentes efeitos práticos que dela se obtinham. $\mathrm{O}$ interesse técnico pelo problema interpretativo naqueles juristas antigos é, contudo, ainda demonstrado pelo fato de que, dentre os vários tipos de interpretação, aquele mais particularmente estudado foi o que oferecia maior apoio a um estudo lógico e, ao mesmo tempo, maior interesse para aplicação prática, isto é, a interpretação extensiva. ${ }^{3}$ A interpretação política é mencionada pela primeira vez nos escritos, em vários aspectos interessantes, sobretudo quanto ao problema interpretativo, pela amplitude das questões abordadas e pela inovação da sistematização, de Joachim Hopper. Porém, enquanto aqueles que adotam o conceito e a expressão interpretação política referem-se a Hopper, no próprio Hopper essa expressão não adquire uma importância particular, tanto que dificilmente teria assumido posteriormente aquele significado especial se outros não tivessem se encarregado de dar a ela peso e evidência.

Hopper, ${ }^{4}$ com uma divisão original, distingue a interpretação em três grandes ramos: scholastica, forensis e politica. Segundo uma caracterização comparativa que ele mesmo propõe, a scholastica é aquela que "a legibus ad principia ascendit", a forensis é aquela que "a legibus ad quaestiones descendit", a politica é aquela que "supra utramque collocata, rem propositam ab una parte ponens, et principia justi et injusti ab altera, tamquam Janus quidem bifrons, nunc haec nunc illa spectat, et quo pacto se habeant inter se dijudicat". ${ }^{5}$ Em suma, enquanto as duas primeiras categorias coincidem aproximadamente com nossas noções de ciência e prática do direito, a terceira, isto é, a interpretação política, escapa ao campo próprio da interpretação estritamente considerada e se apresenta como valoração crítica das leis. Estudando-a em particular, Hopper atribui a ela duas tarefas específicas: em primeiro lugar, julgar "utrum leges latae recte se habeant nec ne"; em segundo lugar, um vez constatada a lei injusta, observar "ecquid mutanda sit nec ne". ${ }^{6}$ Trata-se de uma interpretação, como se pode ver, que é útil para o Estado e, como tal, requer um conhecimento particular dos assuntos públicos que só pode ser encontrado no homem formado na vida política e introduzido aos seus arcana principis; não pode, portanto, ser realizada pelo jurista técnico, mas apenas por aquele estudioso do direito versado na vida pública e que pode elevar-se àquela mesma visão das leis que é necessária ao legislador. ${ }^{7}$

3 Para maiores esclarecimentos, v. meu escrito L'Analogia nella logica del diritto, Torino, 1938, Parte I.

4 As obras de HOPPER a consultar sobre esse assunto são principalmente: In veram jurisprudentiam Jsagoges ad filium, libri octo, Coloniae, apud Matemum Cholinum, 1580; e Seduardus sive de vera jurisprudentia ad regem, libri duodecim, Antverpiae, in officina. Plantiniana apud viduam et Joannem Moretum, 1590.

5 In veram jurisprudentiam, cit., 1. II, tit. 36, p. 372.

6 Seduardus, cit., 1. IV, tit. 23, p. 122. De modo diverso, na outra obra, In veram jurisprudentiam, distingue-se a interpretação política entre "nomotetica", que "circa leges condendas, corrigendas, tollendas versatur", e "dicastica", que "circa leges conditas, interpretandas, adiuvandas, supplendas, versatur” (loc. cit.). Mas a definição sobre a qual se apoia Conring é a de Seduardus.

7 As distinções originais de Hopper são acolhidas por Martino Antonio DEL RIO, Exercitatio ad l. contractus 23 D. de diversis regulis juris antiqui, Lugduni, apud Franciscum le Feure, 1589: o último capítulo da obra é dedicado à interpretação política das leis em questão. Ele também é autor de um Epitome ex libris I et II elementorum juris cl. j. c. Joachimi Hopperi, nunquam prius editis. Este epítome foi publicado em uma coletânea de seus escritos que traz na página de título: Ex miscellaneorum scriptoribus digestorum, codicis et institutionum juris civilis interpretatio collecta, Paris, apud Michaelem Sonnium, 1580. Do estudo desses livros de Hopper, 
5. - Depois de Hopper, chama atenção à interpretação política Hermann Conring, que ocupa um lugar importante tanto na história do pensamento político alemão, por ter sido um teórico da razão de Estado, ${ }^{8}$ quanto na história da ciência jurídica, por ter defendido célebre doutrina acerca da origem do direito romano nos países germânicos, o que faz com que seja considerado o principal precursor do movimento pelo direito germânico. Como teórico da razão de Estado e jurista, ele estava naturalmente disposto a reconhecer a importância da valoração política das leis e, assim, a adotar e divulgar a noção hopperiana de interpretatio politica. Em algumas de suas obras menores de teoria jurídica, ele mostra ter derivado propriamente de Hopper as principais sugestões. ${ }^{9} \mathrm{Na}$ teoria, a importância do elemento político no estudo do direito o conduz até mesmo a considerar a verdadeira jurisprudentia como um ramo da civilis prudentia, que é a teoria e a arte da política em geral, atribuindo-lhe como tarefa principal o juízo acerca da utilidade e da inutilidade das leis em relação ao seu fim político, e, portanto, designando a interpretação política quase como sua função exclusiva. A jurisprudência como comumente entendida, ou seja, o comentário do direito positivo, ele chama de juris peritia, relegando-a, como uma doutrina inferior, ao campo da filologia e da gramática.

Contudo, o melhor comentário a essa nova forma de interpretatio é um breve escrito ${ }^{10}$ em que Conring, tomando como objeto de exegese uma lei imperial romana, aplica, de modo prevalente dentre os outros tipos de interpretação, a interpretação política, esclarecendo melhor com o exemplo do que com qualquer outra explicação teórica o que ela realmente é e quais resultados ela alcança. A lei comentada é uma constituição dos imperadores Valentiniano, Valente e Graciano inserida no Codex Theodosianus, tit. De studiis liberalibus urbis Romae et Constantinopolitanae (XIV, 9, I). A princípio, ela é examinada do ponto de vista das três causas, a material, a eficiente e a formal, e, até esse ponto, o comentário é essencialmente histórico e teleológico. Porém, a seguir, em correspondência com a advertência do próprio Conring segundo a qual, depois da "interpretatio historica vel grammatica", voltada a elucidar a mens legis, deve intervir, para que o exame da lei seja completo, a interpretatio politica, pela primeira vez reconhecida e referida em homenagem a Hopper, ${ }^{11}$ entra em jogo a valoração das leis, a partir da qual o próprio intérprete, uma vez aceitos e reconhecidos os fins gerais e particulares que

\footnotetext{
ele adverte "quos ille mihi olim Mantuae Carpetanorum legendos utendosque commodarat" "illa mostra exercitatio ad 1. contractus fuit compósita”. Esses Elementa juris ou, como também os chama no título expresso no princípio do epítome, De principiis sive elementis juris, que ele considera até então não impressos, vieram a lume no mesmo ano de 1580, uma vez que não são nada mais do que o resumo dos livros V e VI da obra In veram jurisprudentiam mencionada acima.

8 MEINECKE, Die Idee der Staatsräson, cit., p. 174 e seg.

9 De civili prudentia, liber unus, 1662; Propolitica seu brevis introductio in civilem Philosophiam, 1663 (citado por STINTZING, Geschichte der deutschen Rechtswissenschaft, II, p. I77).

10 Hermannus CONRINGIUS, Dissertatio ad legem I Codicis Theodosiani De studiis liberalibus urbis Romae et Constantinopolis, Helmestadii, 1655.

11 "Quod ipsum non sine singulari quadam animi voluptate videmus jam etiam ante nos agnovisse summum virum et aeternum Frisiae nostrae decus Joachimum Hopperum, numquam satis laudandi scripti de vera Jurisprudentia lib. IV, tit. 16 e 23” (op. cit., p. 56).
} 
a lei deve buscar, emite juízo sobre a sua maior ou menor oportunidade. A interpretação política não é, portanto, como poderia parecer pelo já exaurido exame das três causas, o estudo da quarta causa ou causa final, mas o estudo da correspondência da lei em sua substância ao fim, ou, como diriam os alemães, da sua Zweckmässigkeit: em outras palavras, a interpretação política, considerando a lei como um instrumento de governo, pergunta se é um instrumento idôneo e, em caso negativo, em que pontos deve ser modificada; como tal, uma vez que busca a conveniência da lei ao Estado, diz respeito não tanto ao doutrinador ou ao juiz, mas sobretudo ao legislador. Conring, em particular, depois de ter percorrido toda a lei com uma investigação histórico-gramatical, reinicia sua análise para valorar passo a passo a sua oportunidade política, quase sempre encontrando correspondência perfeita entre o fim proposto e os meios empregados, e só aqui e ali, muito raramente, destacando os defeitos, por exemplo no que diz respeito às penalidades estabelecidas, que lhe parecem muito duras.

6. - Por fim, a teoria da interpretação política é objeto de um tratamento particular e de um exame mais detalhado na opereta do jurista germanista Christoph Peller, ${ }^{12}$ que, embora queira dar pela primeira vez uma sistematização completa ao problema da interpretação política, não esconde que seu principal projeto é mover uma crítica geral à jurisprudência romanística; a interpretação política, que é a valoração das leis de acordo com o fim político e, portanto, em conformidade com as necessidades da razão de Estado, serve diretamente para examinar a tendência predominante da jurisprudência de aceitar servilmente os princípios legislativos da era imperial sem uma crítica histórica preliminar. Já no prefácio, dando um olhar introdutório sobre a situação da teoria da interpretação, destaca as duas causas fundamentais da sua decadência, das quais a primeira consiste precisamente no "nimia et superstitiosa quaedam veneratio juris romani", o que depois lhe permite lutar contra muitos dos dogmas mais atuais da doutrina da interpretação (cap. I, $\S \S 6-14),{ }^{13}$ e a segunda consiste no "neglectus studii politici in demonstrandis fundamentis et rationibus legum". A partir desta segunda razão para o erro, surge toda a discussão mais apropriadamente dirigida à teoria da interpretação política, à qual a segunda parte é dedicada (cap. II, §§ 15-31).

A principal razão que justifica a introdução da interpretação política reside numa consi-

12 Christophorus Godofredus PELLERUS, De interpretatione legum politica, Altdorf, 1719 ("Dissertatio juridica publica et solemnis de interpretatione legum politica, quam auctoritate magnifici jctorum ordinis in illustri universitate altorfina placido eruditorum examini submittit die XXIII maji A.R.S. MDCCXIX H.L.Q.C. Christophorus Godofredus Pellerus de Schoppershof, literis magni Danielis Meyeri”). Não confundir, por razões óbvias de tempo, com o outro mais conhecido Christophorus PELLERUS, autor do trabalho Politicus sceleratus impugnatus, id est Compendium politices novum, II ed., Norimbergae, apud Johannem Andream Endterum et Wolfgangi Jun. Haeredes, 1665.

13 Concentrando-se acima de tudo em três questões, nas quais ele traz um ponto de vista original: sobre a distinção entre interpretação autêntica, usual e doutrinal, que ele combate argumentando que a interpretação só pode ser doutrinal; sobre o conceito de interpretação extensiva, que nega em favor da interpretação declarativa apenas; sobre a regra "favorabilia sint extendenda, odiosa restringenda", que rejeita por considerá-la como uma regra não geral, mas adequada ao direito romano e não transmissível por ele a outros direitos. 
deração de natureza geral, sobre a qual não há dúvida de que a teoria da política, agora madura, atuou. A lei, de acordo com Peller, repousa, de fato, sobre dois fundamentos, a ratio moralis e a ratio civilis: "illa sese fundat in aequitate, et exinde propullutante doctrina morali; altera vero in utilitate civili seu ratione status publici, et hanc respiciente prudentia politica" (p. 30). Ora, o fato, diz Peller, de que a maior parte dos intérpretes sob influência romanística só levou em conta o primeiro não implica que mesmo este último não tenha seu grande peso para a valoração exata das leis. E é precisamente sob este segundo aspecto que a nova perspectiva que ele propõe é apresentada. Se é ofício do jurista examinar as leis de um Estado em sua efetividade para poder dar uma valoração que seja útil ao próprio Estado, é necessário investigar não somente se a lei é justa ou não, mas também, tratando-se não de leis naturais, mas de leis positivas, em vigor em um dado Estado, se está em conformidade ou não com os fins do Estado, isto é, não apenas se é moralmente honesta, mas também se é politicamente oportuna. Daí vem uma nova tarefa para o jurista tradicional, a interpretação política, que é definida por Peller: "ea pars jurisprudentiae universalis, vi cuius in primis rationes legum, politicas et arcanas inquirimus, et pro convenientia aut disconvenientia earum tum maxime cum ratione status publici cum et reliquis prudentiae legislatoriae partibus, de utilitate aut noxa earum judicamus, ad veram et perfectam juris et legum prudentiam consequendam" (p. 82). A partir dessa definição, podemos deduzir que a tarefa do intérprete é descobrir as razões políticas de uma lei para poder julgar sua conveniência em relação à razão de Estado, ou sua maior ou menor utilidade: o que significa antes de tudo que o jurista pode colocar-se acima da lei para manifestar um juízo. Contra a doutrina comum do intérprete-exegeta, fiel reprodutor do conteúdo da lei, Peller se insurge vigorosamente, observando que somente em Estados despóticos não é permitido aos juristas examinar as profundas razões das leis, mas que precisamente nessas condições os juristas "liberalem juris scientiam in servilem leguleismum convertunt qui sterili cortici verborum inhaerendo vim ac potestatem eorum negl git" (p. 51); e conclui que a interpretação política deve ser supremamente admitida naqueles Estados que usam leis estrangeiras, como foi o caso das leis justinianas na Europa de seu tempo, e especialmente nos Estados germânicos, dado que a natureza dos Estados é muito diferente e o que é conveniente para um não necessariamente convém aos outros.

O ponto de referência para uma valoração política da lei é a razão de Estado. Em outras palavras, a interpretação política consiste em confrontar a ratio legis e a ratio status para medir a sua maior ou menor correspondência, da qual advém o juízo sobre a maior ou menor oportunidade política ou utilidade da lei. Uma lei que não se conforma à razão de Estado deve ser submetida à mesma depreciação a que se submetem, por uma longa tradição de crítica, leis injustas ou leis que não correspondem à razão natural: portanto, além da razão natural, a razão de Estado ou política oferece um novo critério para a valoração crítica das leis. Em suma, à tradicional 
subsunção do direito à moralidade é acrescentada a nova subsunção do direito à política. No que diz respeito à teoria da razão de Estado, Peller não tem novas ideias: na esteira da copiosa literatura alemã sobre o assunto, ele define a razão de Estado: "psae prudentiae civilis nobilissima pars, quae modum demonstrat, quo utilitas seu finis reipublicae obtinetur" (p. 56) e aceita a distinção usual em "geral" e "especial", a primeira universalmente comum a todos os Estados, a segunda variável em relação à diversidade de Estados, ou melhor, em relação à variedade de formas de governo (fim interno) ou aos desejos do príncipe (fim externo). As principais regras da interpretação política são precisamente construídas sobre essas distinções fundamentais da razão de Estado: vale dizer, a utilidade da lei deve ser comensurada primeiro em vista da razão de Estado geral, depois da especial, e o intérprete deve, em primeiro lugar, conhecer os fins que o Estado se propõe, em segundo lugar, recorrer às fontes da sabedoria política para saber quais são os princípios do Estado em questão e, apenas ao final, sopesar cada lei para verificar se esses objetivos foram alcançados e se esses princípios estão seguros.

Entende-se que todo o tratamento teórico é feito por Peller com a segunda finalidade de dar uma contribuição à crítica da recepção do direito romano nos Estados germânicos, dos quais Conring, cujos traços Peller segue muito de perto, havia dito que "cum incautius Romanorum illa monarchica justo plura admisissent, magnam pristini status jacturam fecerint” (p. 102), ressaltando a importância de uma interpretação que vá além da lei para valorar sua conveniência política. Mas o fato é que, mesmo do ponto de vista estritamente teórico e com atenção exclusiva à doutrina da interpretação, o significado desse episódio na história da ciência do direito não deve ser negligenciado, sobretudo porque nos permite vislumbrar um reflexo da tão clamorosa doutrina da razão de Estado na esfera muito mais descuidada e inobservada da ciência jurídica.

7. - Essa nova categoria de interpretação das leis, como resulta de alguns testemunhos reunidos aqui e ali, teve que entrar em uso na ciência jurídica alemã porque precisamente na Alemanha, com o despertar do espírito nacionalista, sentiu-se a estranheza do Direito romano mais que em outros países e, assim, tornou-se necessária uma valoração do "Corpus Juris" não apenas do ponto de vista do direito natural, mas também de um ponto de vista estritamente político. Mas ela não teve grande difusão nem vida longa. Glück, em seu Comentário das Pandectas, ainda a recorda, notando que, além da interpretação gramatical e lógica, "muitos acrescentam uma terceira espécie, à qual chamam de interpretação política", e a define da seguinte forma: "trata-se daquele modo de interpretação que indaga se e em que medida as leis, as quais nós usamos, são adequadas à nossa atual constituição e às condições atuais e se são, portanto, aplicáveis ou não". ${ }^{14}$ Glück, pessoalmente, apesar de não esconder sua importância, acredita

14 GLÜCK, Ausführliche Erläuterung der Pandecten, I T., II ed., Erlangen, 1797, p. 226 (trad. it., Commentario alle Pandette, 
que ela não forma uma espécie particular de interpretação doutrinária e, assim, a inclui no vasto âmbito da interpretação lógica. ${ }^{15}$

A menção no grande tratado de Glück é talvez a última. No sistema de Savigny, ela foi completamente esquecida. E a partir de Savigny, que também na teoria da interpretação inicia uma verdadeira tradição e abre caminho para imitadores, ela passará pelo silêncio de toda a pandectística posterior, até que se perca dela qualquer traço, a ponto de aparecer hoje nessa breve exumação como uma pura curiosidade histórica. Além disso, seu desaparecimento não é acidental, dado que durante o período de reformas ela já havia exaurido sua tarefa, que foi abrir a brecha e dar espaço para a crítica das leis no ambiente tradicionalista e conservador da ciência jurídica. Quando a crítica das leis, com a era do Iluminismo reformista, assumiu um papel preponderante na história da ciência jurídica, sob o impulso das teorias jusnaturalistas, aquele material que até então podia ser situado na doutrina da interpretação e, assim, legitimado com a utilização de antigos esquemas, teve que ser considerado por si mesmo, dada sua importância e suas proporções, e constituiu-se como ciência autônoma, separada da ciência jurídica e denominada em uma de suas especificações mais típicas: "ciência da legislação". Mesmo hoje, permanece a separação entre a ciência jurídica propriamente dita, que inclui toda a doutrina tradicional da interpretação, e a política jurídica, que inclui a crítica das leis vigentes do ponto de vista dos interesses e fins do Estado, e tendo em conta o jus condenum: é certo que a interpretação política, embora limitada em sua origem e em seu breve desenvolvimento aos interesses particulares do direito germânico, é um ancestral distante da assim chamada política jurídica, e formou-se nessa mesma atmosfera de intenso interesse em assuntos públicos e princípios políticos da qual as teorias da razão de Estado foram a manifestação mais clara.

Milano, 1888, I, p. 182).

15 Glück cita entre os defensores da interpretação política, além de Peller, SCHILTER [na edição italiana está escrito erroneamente Schiller (Johann Schilter, um dos mais célebres representantes do direito alemão no século XVII)], Praxis juris romani in foro Germanico, ex. II, § 8, nota a (a I ed. é de 1675-1683, Jena); e HARTLEBEN, Meditationes ad Pandectas, spec. II, med. 3. Esta citação não é exata: trata-se evidentemente do conhecido trabalho de Augustin LEYSER, intitulado precisamente Meditationes ad Pandectas, em II vols., publicado entre 1717 e 1748 e apenas parcialmente comentado por Hartleben em uma edição de Frankfurt de 1778-1781. Pude ler um amplo e mais antigo tratado sobre interpretação política no trabalho de Vincentius PLACCIUS, De jurisconsulto perfecto, sive interpretatione legum in genere, liber singularis, II ed., Holmiae et Hamburgi, apud Gottfried Liebezeit, 1693, cap. IV, add. IX. Situa a interpretatio politica na categoria da interpretação mental e a define: "Politica interpretatio, sive statistica (hodierno loquendi more) interpretatio, est mentalis assignans rationem legi politicam, sive ex ratione status petitam" (p. 105). 